\title{
Parameter identification of large-scale magnetorheological dampers in a benchmark building
}

\author{
Arash Bahar ${ }^{a}$, Francesc Pozo ${ }^{\mathrm{b}, *}$, Leonardo Acho ${ }^{\mathrm{b}}$, José Rodellar ${ }^{\mathrm{a}}$, Alex Barbat ${ }^{\mathrm{c}}$ \\ ${ }^{a}$ CoDAlab, Departament de Matemàtica Aplicada III, Escola Tècnica Superior d'Enginyers de Camins, Canals i Ports de Barcelona (ETSECCPB), \\ Universitat Politècnica de Catalunya (UPC), Jordi Girona, 1-3, 08034 Barcelona, Spain \\ ${ }^{\mathrm{b}}$ CoDAlab, Departament de Matemàtica Aplicada III, Escola Universitària d'Enginyeria Tècnica Industrial de Barcelona (EUETIB), Universitat Politècnica de Catalunya, \\ Comte d'Urgell, 187, 08036 Barcelona, Spain \\ ' CIMNE, Departament de Resistència de Materials i Estructures a l'Enginyeria, Escola Tècnica Superior d'Enginyers de Camins, Canals i Ports de Barcelona, \\ Universitat Politècnica de Catalunya, Jordi Girona, 1-3, 08034 Barcelona, Spain
}

\section{A R T I C L E I N F O}

\section{Article history:}

Received 5 February 2009

Accepted 7 October 2009

Available online 11 November 2009

\section{Keywords:}

MR damper

Parameter identification

Benchmark building

\begin{abstract}
A B S T R A C T
Magnetorheological (MR) dampers are devices that can be used for vibration reduction in structures. However, to use these devices in an effective way, a precise modeling is required. In this sense, in this paper we consider a modified parameter identification method of large-scale magnetorheological dampers which are represented using the normalized Bouc-Wen model. The main benefit of the proposed identification algorithm is the accuracy of the parameter estimation. The validation of the parameter identification method has been carried out using a black box model of an MR damper in a smart base-isolated benchmark building. Magnetorheological dampers are used in this numerical platform both as isolation bearings as well as semi-active control devices.
\end{abstract}

(c) 2009 Elsevier Ltd. All rights reserved.

\section{Introduction}

Magnetorheological (MR) dampers are devices that change their mechanical properties when they are exposed to a magnetic field. The magnetorheological fluid of these actuators is characterized by a great ability to vary, in a reversible way, from a free-flowing linear viscous liquid to a semi-solid one within milliseconds [1]. Moreover, MR dampers have a low cost, low power requirements, large force capacity, robustness and can be controlled with a low voltage at the coils [1]. All these features make MR dampers very attractive and promising as actuators controlled by the voltage that can be used in different engineering fields, such as dampers and shock absorbers (pressure driven flow mode devices), as well as clutches, brakes, chucking, and locking devices (direct-shear mode devices) [9]. From a structural control point of view, MR dampers are usually employed as actuators operated by low voltages. In this respect, semi-active control systems seem to combine the best compromise between passive and active control: they offer the reliability of passive devices together with the versatility and adaptability of active systems $[3,5,20]$. However, the first step in the

\footnotetext{
* Corresponding author.

E-mail addresses: arash.bahar@upc.edu (A. Bahar), francesc.pozo@upc.edu (F. Pozo), leonardo.acho@upc.edu (L. Acho), jose.rodellar@upc.edu (J. Rodellar), alex.barbat@upc.edu (A. Barbat).

URLs: http://www-ma3.upc.es/codalab (F. Pozo), http://www.cimne.upc.es (A. Barbat).
}

design of a semi-active control strategy is the development of an accurate model of the MR device. It is worth noting that the system-identification issue plays a key role in this control problem [19]. High-accuracy models can be designed using two different model families: semi-physical models $[16,20]$, and black box models $[10,22]$. Some of the most known semi-physical models to describe the hysteretic behaviour of MR dampers are the Bingham model and its extended versions, the Bouc-Wen model, the Dahl model, the modified LuGre model and some other non-parametric models [12,17]. It is important to remark that these models are not linear-in-parameters and, therefore, classical parameter identification methods, such as the gradient or the mean square algorithms, cannot be applied.

Using a normalized version of the Bouc-Wen model, Ikhouane and Rodellar [7] present an identification algorithm which is directly used for MR dampers in shear-mode [17]. However, this methodology can produce large parameter identification errors if the viscous friction is much smaller than the dry friction [17]. To cope with this drawback, a modified step was proposed by Rodríguez et al. [17] and tested in a small-scale MR damper. When the identification is applied to a large-scale MR damper, the parameter identification errors increase [18]. The aim of this paper is to improve the accuracy of the identification algorithm. This is based on augmenting the normalized Bouc-Wen model with an additional term. The validation of this modified parameter identification method has been carried out using a black box model of an MR damper in a smart base-isolated benchmark building [14]. This 
model is unknown for the user of this benchmark and for the designer of control systems. The benchmark platform is then considered as a virtual laboratory experiment. The numerical results show that the proposed modified method is able to improve significantly the accuracy of the parameter identification.

The paper is organized as follows: in Section 2, the magnetorheological damper model is presented. In Section 3, the key points of the modified identification method are discussed. In Section 4, the application of the proposed identification method to a large-scale MR damper in a benchmark building is considered. Finally, some concluding remarks are stated in Section 5.

\section{The magnetorheological damper model}

The normalized version of the Bouc-Wen model [7] is an equivalent representation of the original Bouc-Wen model [22]. For MR dampers in shear mode it takes the form:

$\Phi_{n}(\dot{x}, w)(t)=\kappa_{\dot{x}}(v) \dot{x}(t)+\kappa_{w}(v) w(t)$

$\dot{w}(t)=\rho\left(\dot{x}(t)-\sigma|\dot{x}(t)||w(t)|^{n-1} w(t)+(\sigma-1) \dot{x}(t)|w(t)|^{n}\right)$,

where $\Phi_{n}(\dot{x}, w)$ is the output force of the MR damper, $\dot{x}(t)$ and $v$ are the velocity and voltage inputs, respectively. The voltage input $v$ is the applied voltage at the coil of the MR damper. The system parameters, which are voltage-dependent, are $\kappa_{\dot{x}}(v)>0, \kappa_{w}(v)>0$, $\rho>0, \sigma>1 / 2$, and $n \geqslant 1$. These parameters control the shape of the hysteresis loop and their meaning can be found in [6]. The state
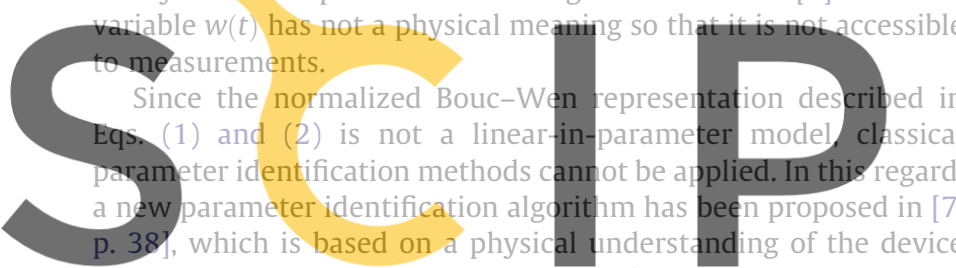

along with a black box description. Rodríguez et al. [18] used this methodology for a large-scale MR damper. The method is based

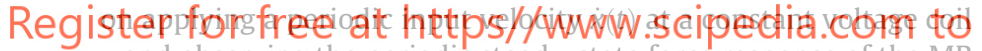
$v$ and observing the periodic steady-state force response of the MR damper. Nonetheless, large relative errors in the identification process can be observed when the MR damper has a viscous friction $\left(\kappa_{\dot{x}}(v) \dot{x}(t)\right)$ small enough with respect to the dry friction $\left(\kappa_{w}(v) w(t)\right)$. To cope with this drawback, when the displacement is large enough, an alternative method based on the plastic region of the force-velocity diagram of the MR damper has been proposed in [17]. However, the model in Eqs. (1) and (2) may not give an accurate representation of large-scale MR dampers which do not belong to the shear-type category. For instance, consider the black box model of an MR damper in the smart base-isolated benchmark building [14]. Fig. 1 contains the force-displacement and forcevelocity diagrams when this MR damper is excited by a sinusoidal displacement and velocity. In order to test the goodness of the Bouc-Wen model, this figure also contains the response of the dynamic model in Eqs. (1) and (2) with some appropriate parameters. It can be observed that the resulting plastic branch in the forcevelocity diagram is wider that the corresponding branch of the Bouc-Wen model. In the literature, the same type of cycles have been experimentally reported, for instance, in [4, Fig. 4b], [11, Fig. 9] and [13, Fig. 7]. Therefore, it can be derived that this kind of hysteretic loops are unable to be reproduced with the original Bouc-Wen model. To improve the accuracy of the model representation and, consequently, the accuracy of the parameter identification, we use the following extended Bouc-Wen model:

$$
\begin{aligned}
& \Phi_{e}(x, \dot{x}, w)(t)=\kappa_{x}(v) x(t)+\kappa_{\dot{x}}(v) \dot{x}(t)+\kappa_{w} w(t), \\
& \dot{w}(t)=\rho\left(\dot{x}(t)-\sigma|\dot{x}(t)||w(t)|^{n-1} w(t)+(\sigma-1) \dot{x}(t)|w(t)|^{n}\right),
\end{aligned}
$$

where the term $\kappa_{x}(v) x(t)$, which represents a linear elastic force, has been added. We consider that the coefficient $\kappa_{x}$ is voltagedependent, as the other parameters. The effect of this term can be

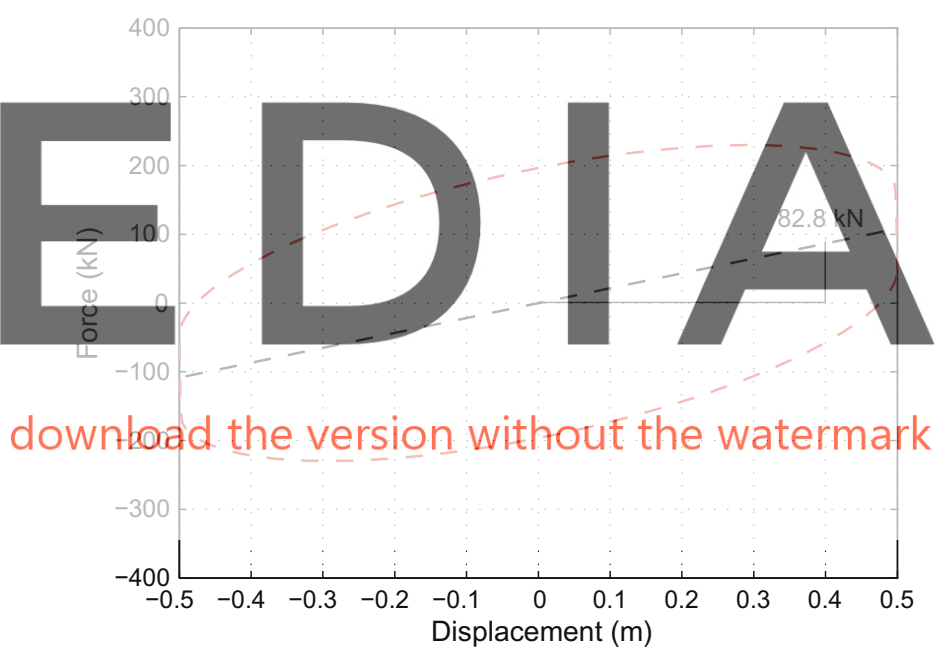

Fig. 2. The average inclination of the force-displacement diagram, when the MR damper is excited by a sinusoidal displacement, gives an estimation of the parameter $\kappa_{x}$
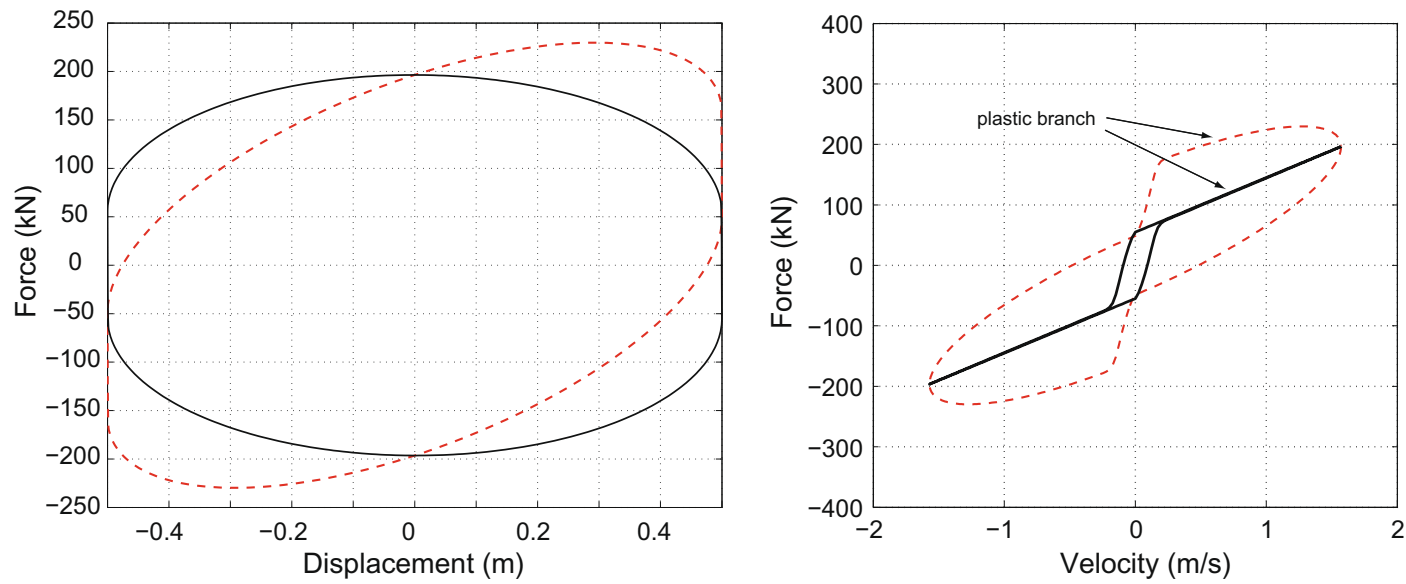

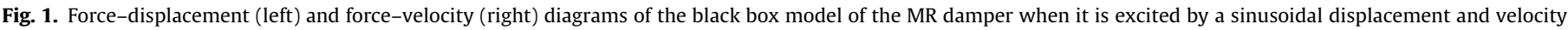
(dashed). The response of the dynamic Bouc-Wen model in Eqs. (1) and (2) under the same excitation is represented by a solid line. 
observed not only in the force-velocity diagram, but also in the force-displacement: the resulting plot is inclined. This feature has also been experimentally reported in, for instance, [2, Fig. 8], [11, Fig. 9] and [13, Fig. 7].

\section{Model parameter identification}

This section is concerned with the computation of the parameters of the extended model in Eqs. (3) and (4). The proposed algorithm will be divided into two steps: (a) the estimation of the value of $\kappa_{x}$ and (b) the estimation of the rest of the parameters based on the identification algorithm in [18].

At constant voltage, the computation of the parameter $\kappa_{x}(v)$ can be performed graphically by considering the force-displacement diagram of the MR damper. When this device is excited by a sinu-

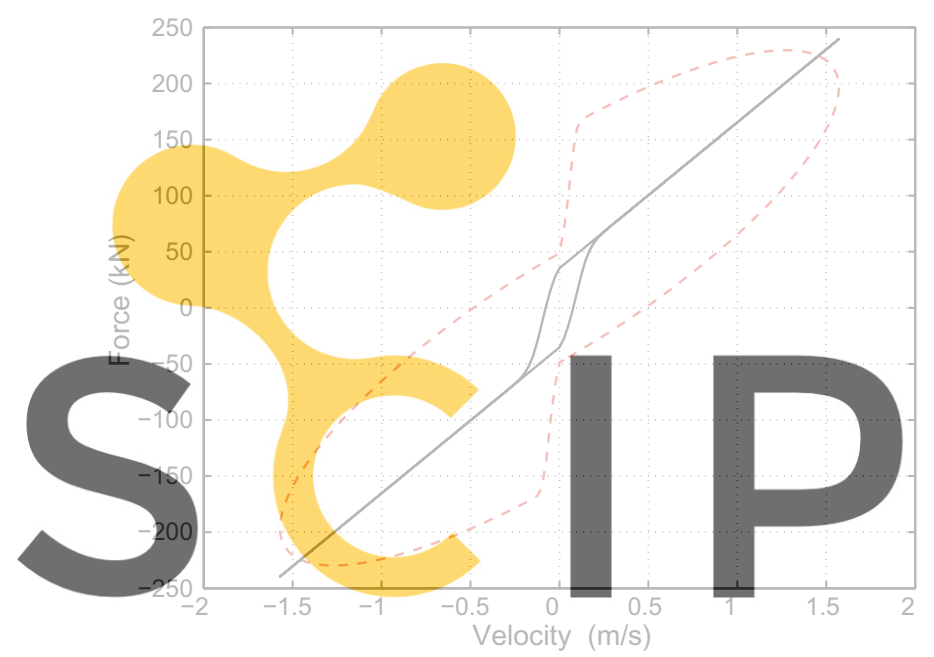

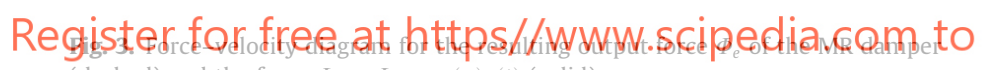
(dashed) and the force $\Phi_{n}=\Phi_{e}-\kappa_{x}(v) x(t)$ (solid).

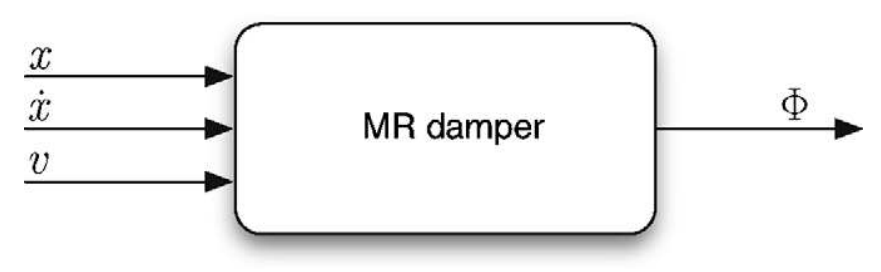

Fig. 4. Input-output variables of the virtual MR damper. soidal displacement with a large enough amplitude, the average inclination of the resulting plot gives an estimation of this parameter. As an example, consider the black box model of an MR damper in the smart base-isolated benchmark building. When this MR damper is driven with zero coil command voltage, we obtain the force-displacement diagram in Fig. 2. The estimated value of $\kappa_{x}$ is then computed as $\kappa_{x}=\frac{82.8}{0.4}=207 \mathrm{kN}$.

To estimate the rest of the parameters, we use the knowledge of the parameter $\kappa_{x}$ and the fact that

$\Phi_{n}(\dot{x}, w)(t)=\Phi_{e}(x, \dot{x}, w)(t)-\kappa_{x}(v) x(t)$.

Fig. 3 depicts (in solid line) the force-velocity diagram for the resulting output force $\Phi_{e}$ of the MR damper minus the linear elastic force $\kappa_{x}(v) x(t)$, when this device is excited by a sinusoidal displacement and velocity. It can be recognized from this figure that this new cycle has the same shape as the force-velocity cycle of the model in Eqs. (1) and (2), which is plotted in Fig. 1 right. As a result, for the identification of the rest of the parameters, that is, the parameters of the model

\section{$\Phi_{n}(\dot{x}, w)(t)=\kappa_{\dot{x}}(v) \dot{x}(t)+\kappa_{w}(v) w(t)$, $\dot{w}(t)=\rho\left(\dot{x}(t)-\sigma|\dot{x}(t)||w(t)|^{n-1} w(t)+(\sigma-1) \dot{x}(t)|w(t)|^{n}\right)$,}

we can follow basically the same idea as in [18]. The details of this method are omitted here but can be found in the Appendix A.

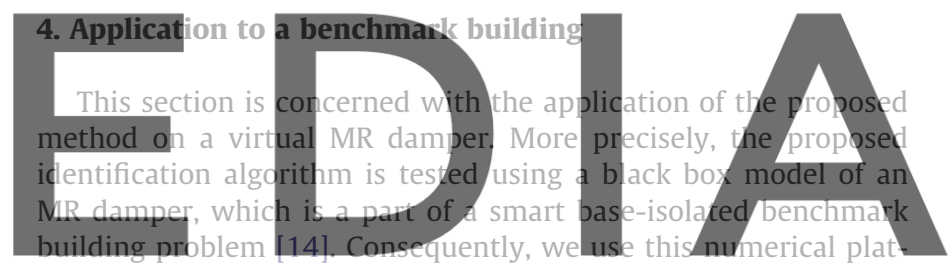

form as a virtual laboratory test (Fig. 4). To validate the results, the output forces of the virtual devise and the identified one will

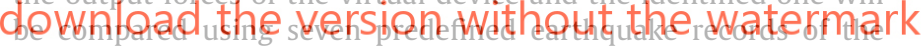
benchmark problem with their corresponding fluctuating voltage during full simulations. The MR damper is used in this context as a semi-active device to reduce the structural response of the building.

\subsection{Smart base-isolated benchmark building}

The smart base-isolated benchmark building [14] is employed as an interesting and more realistic example to further investigate the effectiveness of the proposed design approach. This benchmark problem is recognized by the American Society of Civil Engineers (ASCE) Structural Control Committee as a state-of-the-art model

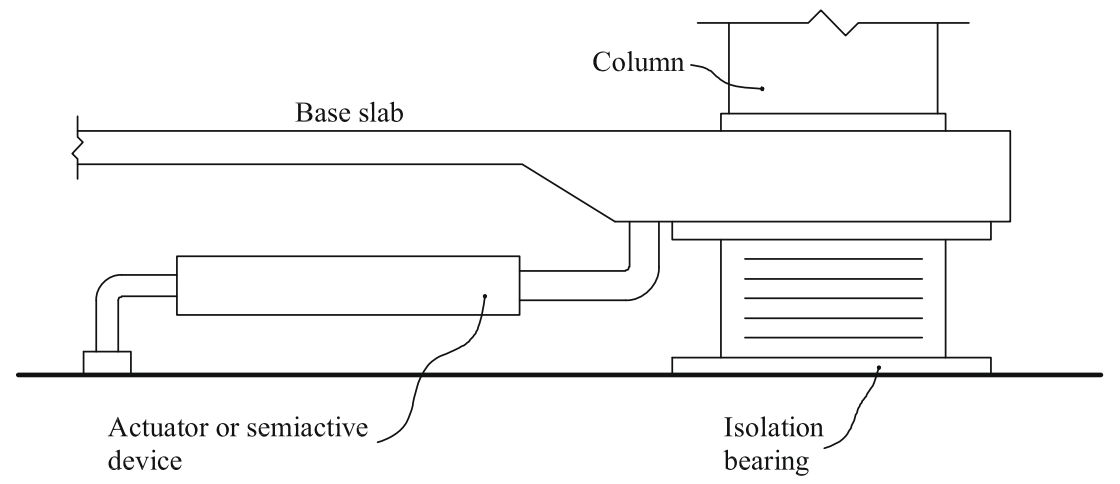

Fig. 5. Elevation view with devices. 

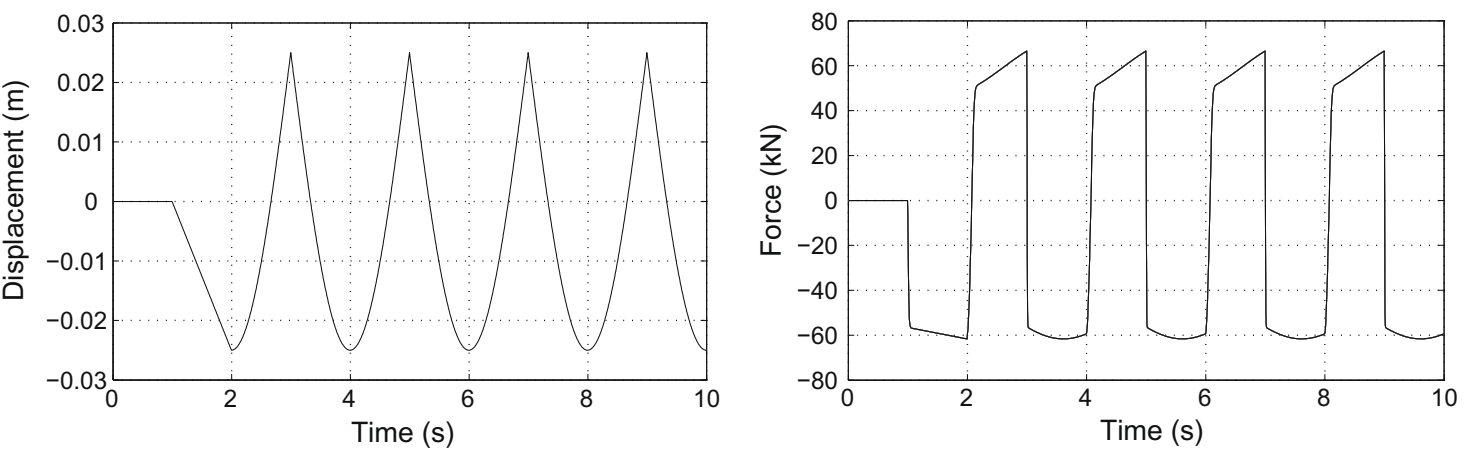

Fig. 6. Response of the MR damper model in the benchmark building platform.

developed to provide a computational platform for numerical experiments of seismic control attenuation [15,21].

The benchmark structure is an eight-storey frame building with steel-braces, $82.4 \mathrm{~m}$ long and $54.3 \mathrm{~m}$ wide, similar to existing buildings in Los Angeles, California. Stories 1-6 have an L-shaped plan while the higher floors have a rectangular plan. The superstructure rests on a rigid concrete base, which is isolated from the ground by an isolator layer, and consists of linear beam, column and bracing elements and rigid slabs. Below the base, the isolation layer consists of a variety of 92 isolation bearings. The isolators are connected between the drop panels and the footings
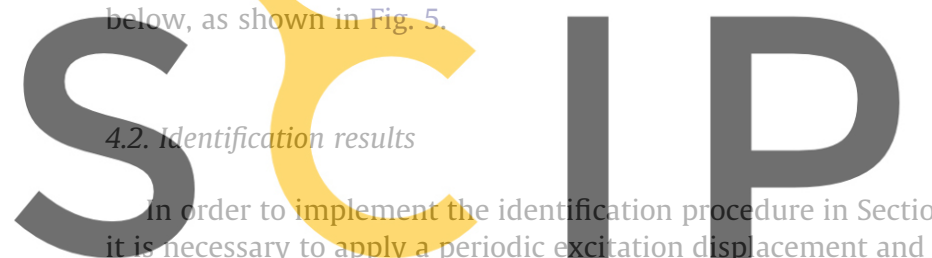
serve the corresponding MR damper force. Fig. 6 illustrates these two signals for a zero voltage. A set of experiments have been per

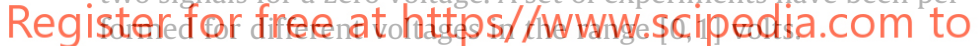

The resulting values of the parameters of the model in Eqs. (3) and (4) are listed in Table 1. Fig. 8 plots these parameters as a function of the voltage. To find an accurate voltage-dependent relation of these parameters, and according with the functional dependence in Fig. 8, we consider that $\kappa_{x}(v)$ is constant, $\kappa_{\dot{x}}(v)$ is linear and $n(v), \rho(v)$ and $\sigma(v)$ are exponential:

Table 1

Identification results

\begin{tabular}{lllllll}
\hline$v$ & $\kappa_{x}$ & \multicolumn{1}{l}{$\kappa_{\dot{x}}$} & $\kappa_{w}$ & $\rho$ & $n$ & $\sigma$ \\
\hline 0.00 & 207 & 89.643 & 54.652 & 644.92 & 1.4557 & 0.7733 \\
0.05 & 207 & 104.24 & 125.97 & 647.34 & 1.4436 & 0.7674 \\
0.10 & 207 & 118.84 & 214.49 & 648.11 & 1.4398 & 0.7656 \\
0.15 & 207 & 133.44 & 313.47 & 648.45 & 1.4381 & 0.7648 \\
0.20 & 207 & 148.04 & 416.96 & 648.64 & 1.4372 & 0.7643 \\
0.25 & 207 & 162.64 & 519.87 & 648.75 & 1.4366 & 0.7641 \\
0.30 & 207 & 177.24 & 617.94 & 648.82 & 1.4362 & 0.7639 \\
0.35 & 207 & 191.84 & 707.73 & 648.87 & 1.4360 & 0.7638 \\
0.40 & 207 & 206.44 & 786.63 & 648.90 & 1.4358 & 0.7637 \\
0.45 & 207 & 221.04 & 852.86 & 648.92 & 1.4357 & 0.7636 \\
0.50 & 207 & 235.64 & 905.48 & 648.94 & 1.4357 & 0.7636 \\
0.55 & 207 & 205.25 & 944.37 & 648.95 & 1.4356 & 0.7636 \\
0.60 & 207 & 264.84 & 970.24 & 648.96 & 1.4356 & 0.7636 \\
0.65 & 207 & 279.44 & 984.64 & 648.96 & 1.4355 & 0.7636 \\
0.70 & 207 & 294.04 & 989.94 & 648.96 & 1.4355 & 0.7636 \\
0.75 & 207 & 308.64 & 989.34 & 648.96 & 1.4355 & 0.7636 \\
0.80 & 207 & 323.24 & 986.89 & 648.96 & 1.4355 & 0.7636 \\
0.85 & 207 & 337.84 & 987.43 & 648.96 & 1.4355 & 0.7636 \\
0.90 & 207 & 352.44 & 996.67 & 648.96 & 1.4355 & 0.7638 \\
0.95 & 207 & 367.04 & 1021.1 & 648.96 & 1.4355 & 0.7636 \\
1.00 & 207 & 381.64 & 1068.2 & 648.98 & 1.4355 & 0.7635 \\
\hline
\end{tabular}

$\kappa_{x}(v)=\kappa_{x}$,

$\kappa_{\dot{x}}(v)=\kappa_{\dot{x}, a}+\kappa_{\dot{x}, b} v$

$n(v)=n_{a}+n_{b} \exp (-13 v)$

$\rho(v)=\rho_{a}+\rho_{b} \exp (-14 v)$

$\sigma(v)=\sigma_{a}+\sigma_{b} \exp (-14 v)$.

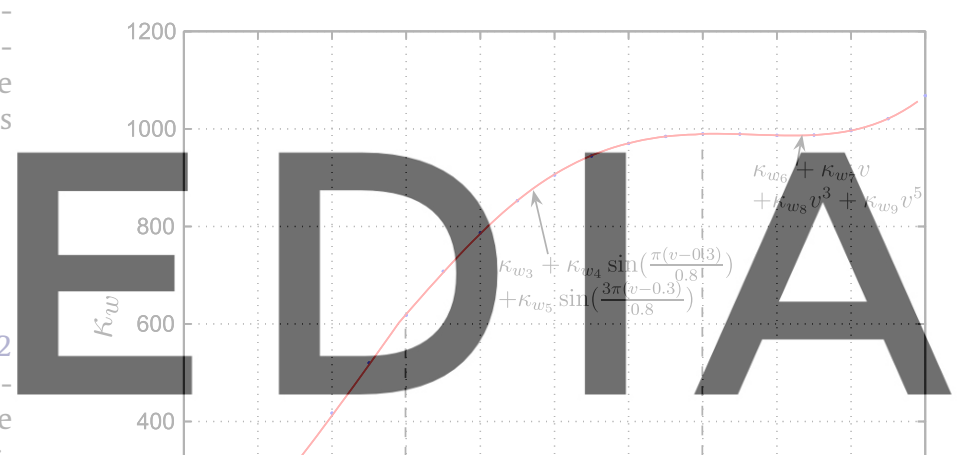

download the version without the watermark 200

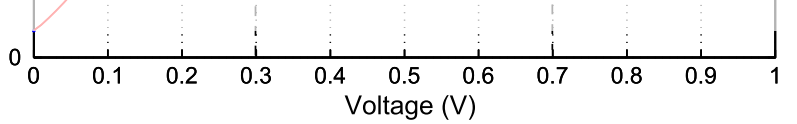

Fig. 7. Results of the parameter identification algorithm.

Table 2

Identification results.

\begin{tabular}{lll}
\hline Parameter & & Value \\
\hline$\kappa_{x}$ & & 207 \\
$\kappa_{\dot{x}}$ & $\kappa_{\dot{x}, a}$ & 89.64 \\
& $\kappa_{\dot{x}, b}$ & 292 \\
$\rho$ & $\rho_{a}$ & 648.95 \\
& $\rho_{b}$ & -3.86 \\
$n$ & $n_{a}$ & 1.44 \\
& $n_{b}$ & 0.02 \\
$\sigma$ & $\sigma_{a}$ & 0.76 \\
& $\sigma_{b}$ & 0.009 \\
$\kappa_{w}$ & $\kappa_{w 1}$ & 55.38 \\
& $\kappa_{w 2}$ & 2270.0 \\
& $\kappa_{w 3}$ & 619.85 \\
& $\kappa_{w 4}$ & 387.34 \\
& $\kappa_{w 5}$ & 18.42 \\
& $\kappa_{w 6}$ & -87.52 \\
& $\kappa_{w 7}$ & 2665.0 \\
& $\kappa_{w 8}$ & -3054.7 \\
& $\kappa_{w 9}$ & 1545.5 \\
\hline
\end{tabular}


Because of the importance of the parameter $\kappa_{w}$ due to its great influence in the resulted force (the range of its magnitude is, approximately, from $50 \mathrm{kN}$ to $1000 \mathrm{kN}$, as can be seen in Table 1), its voltage dependence function has been estimated in three different regions

$\kappa_{w}(v)= \begin{cases}\kappa_{w_{1}}+\kappa_{w_{2}} v^{1.15}, & v \leqslant 0.3 \\ \kappa_{w_{3}}+\kappa_{w_{4}} \sin \left(\frac{\pi(v-0.3)}{0.8}\right)+\kappa_{w_{5}} \sin \left(\frac{3 \pi(v-0.3)}{0.8}\right), & 0.3 \leqslant v \leqslant 0.7, \\ \kappa_{w_{6}}+\kappa_{w_{7}} v+\kappa_{w_{8}} v^{3}+\kappa_{w_{9}} v^{5}, & 0.7 \leqslant v\end{cases}$

based on the variation of the resulted values (Fig. 7).

The coefficients $\kappa_{\dot{x}, a}, \kappa_{\dot{x}, b}, \kappa_{w 1}, \ldots, \kappa_{w 9}, n_{a}, n_{b}, \rho_{a}, \rho_{b}, \sigma_{a}$ and $\sigma_{b}$, which are listed in Table 2, can be computed using MATLAB. The voltage-dependent functions are plotted in Fig. 8.
Table 3

Error norm $(\varepsilon)$ for the proposed parameter identification.

\begin{tabular}{llllllll}
\hline & Newhall & Sylmar & El Centro & Rinaldi & Kobe & Jiji & Erzinkan \\
\hline FP- $x(\%)$ & 6.47 & 5.67 & 7.78 & 7.12 & 6.52 & 3.61 & 4.88 \\
FP- $y(\%)$ & 3.84 & 8.44 & 7.90 & 5.67 & 7.85 & 4.02 & 5.35 \\
\hline
\end{tabular}

\subsection{Model validation}

The identification models presented in the literature usually have good accuracy when they consider a constant voltage. However, because of the role of MR dampers as a semi-active devices in structural control systems, the final identified model has to be checked under a simulated condition using, for instance, an earthquake record and the corresponding fluctuating command voltage
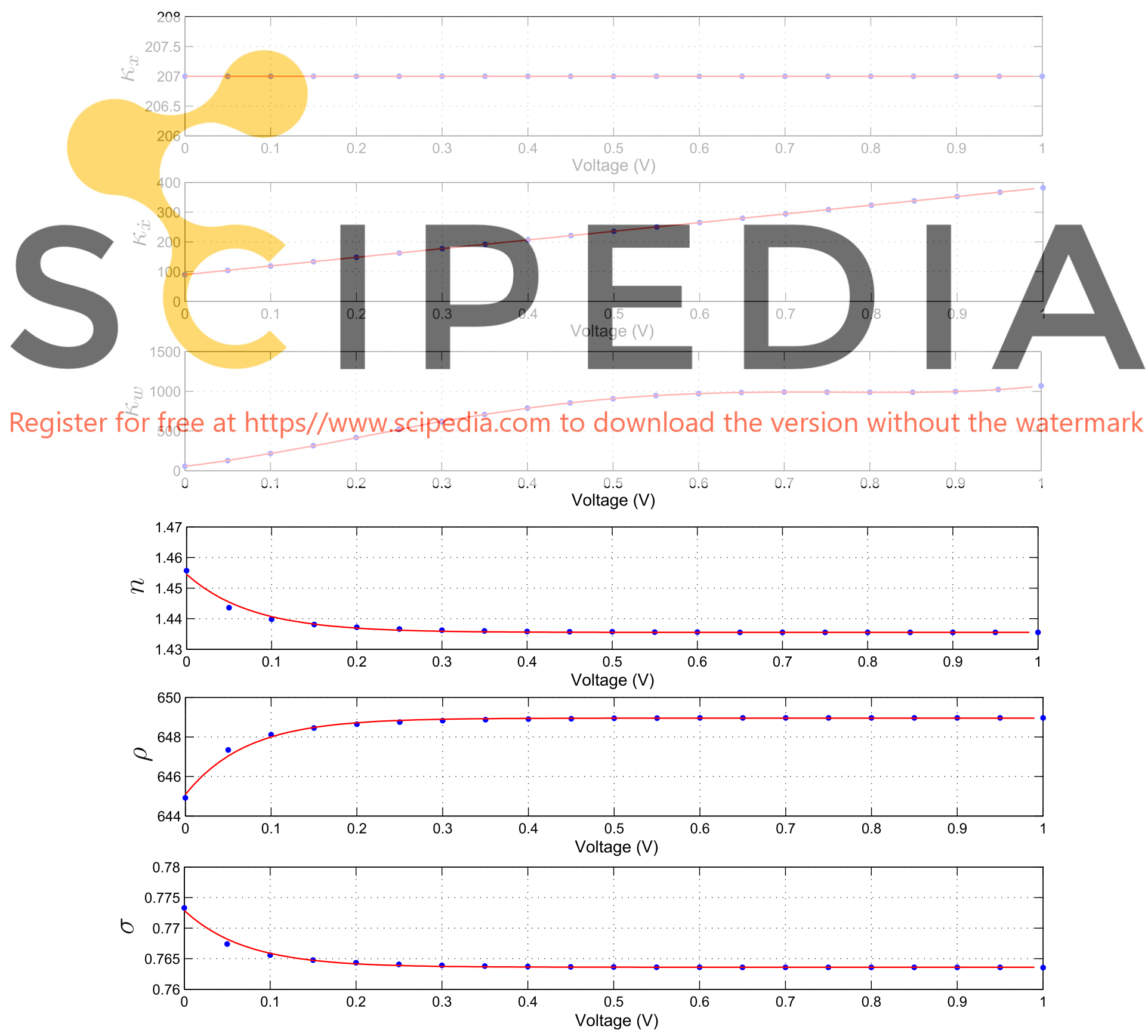

Fig. 8. Results of the parameter identification algorithm. 

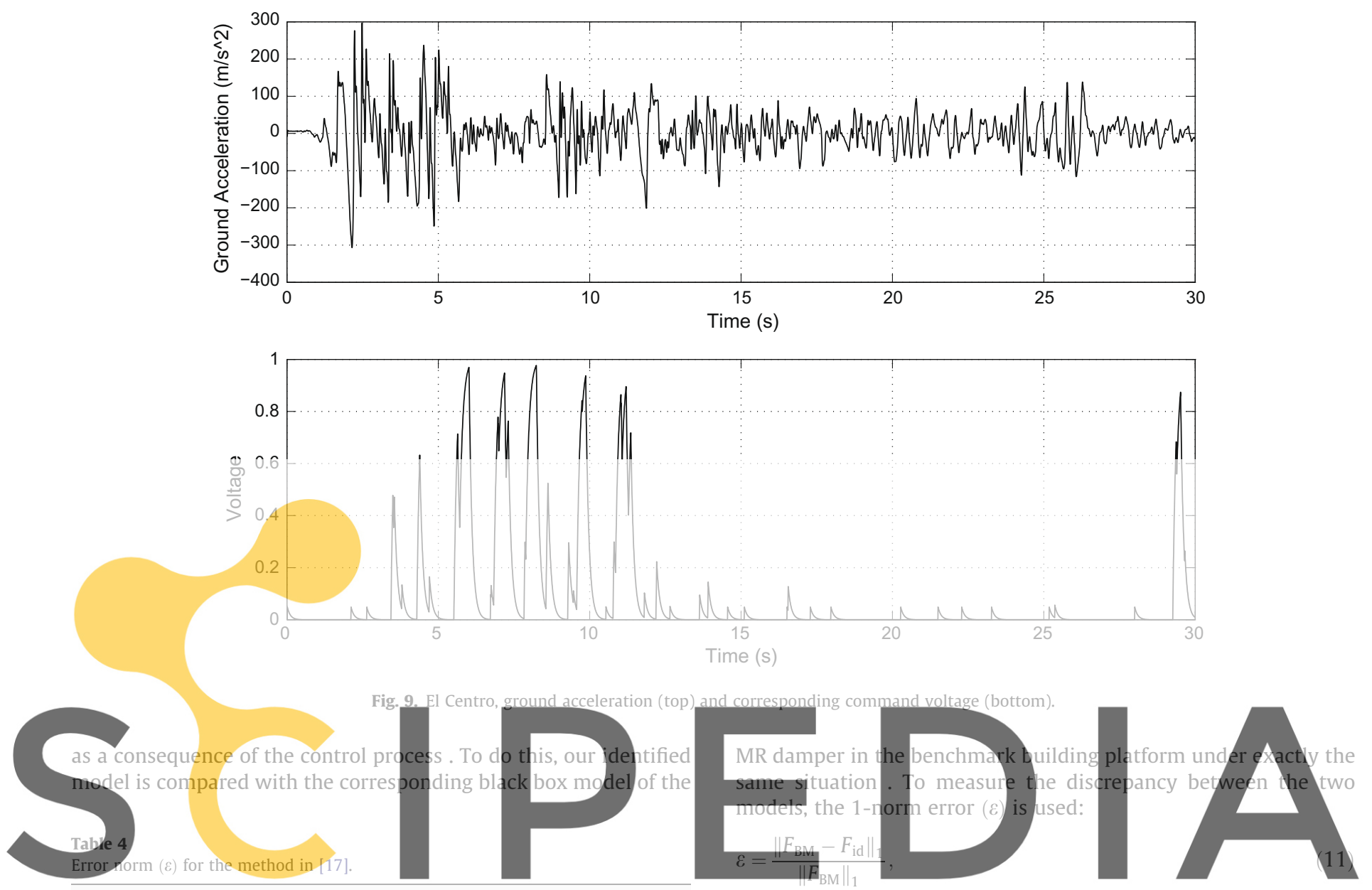

$$
\text { Newhall Sylmar El Rinaldi Kobe Jiji Erzinkan }
$$

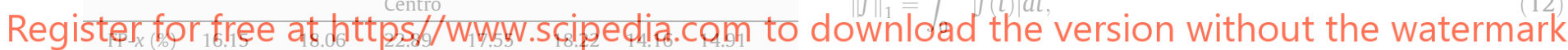

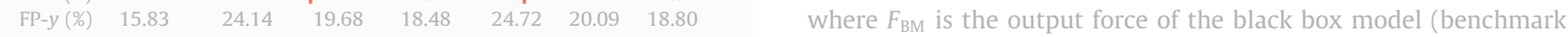
building platform) and $F_{\text {id }}$ is the resulting force of the identified
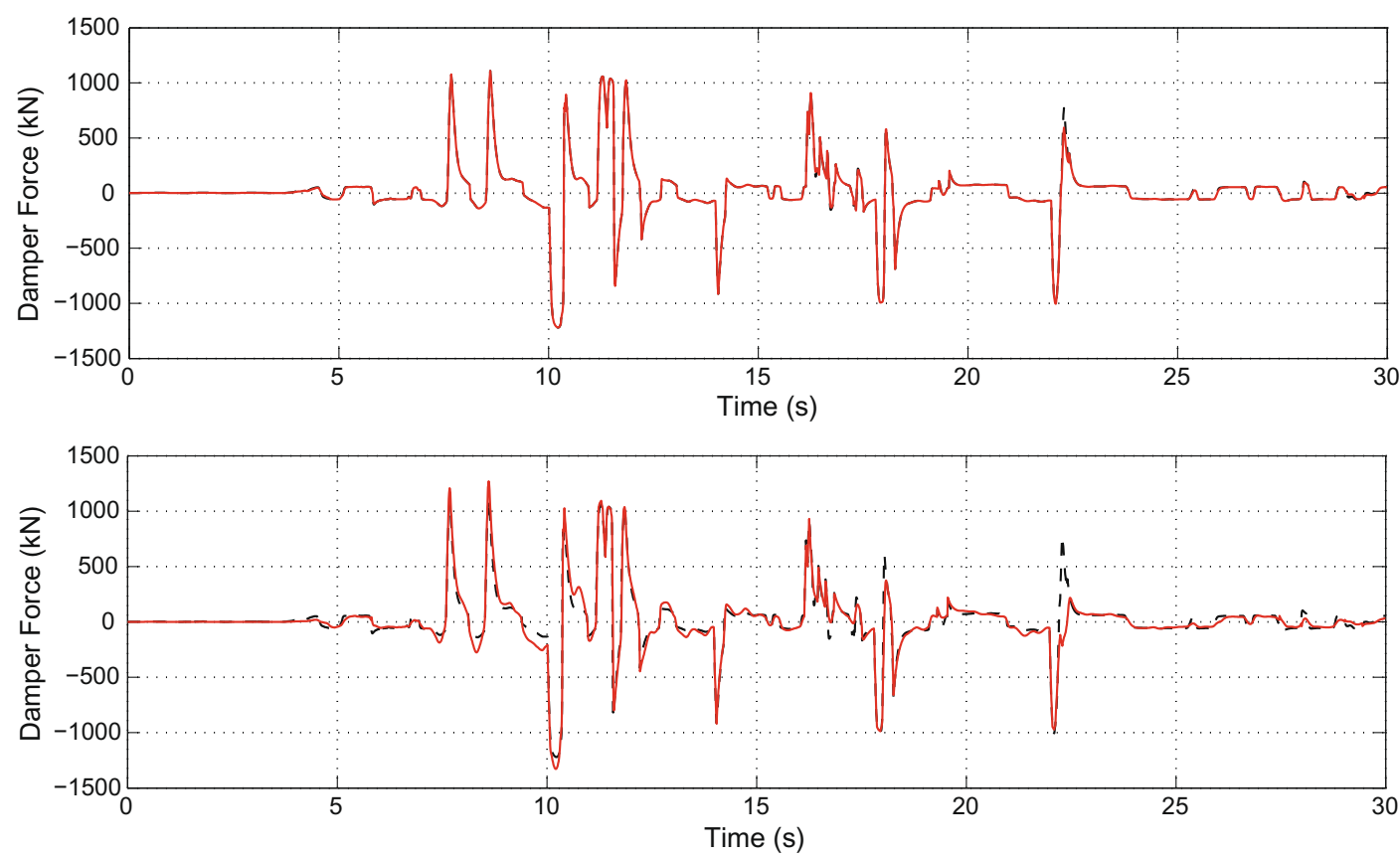

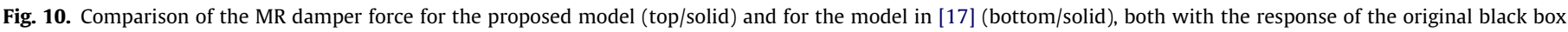
model (dashed), under Kobe ground motion (FP-y). 

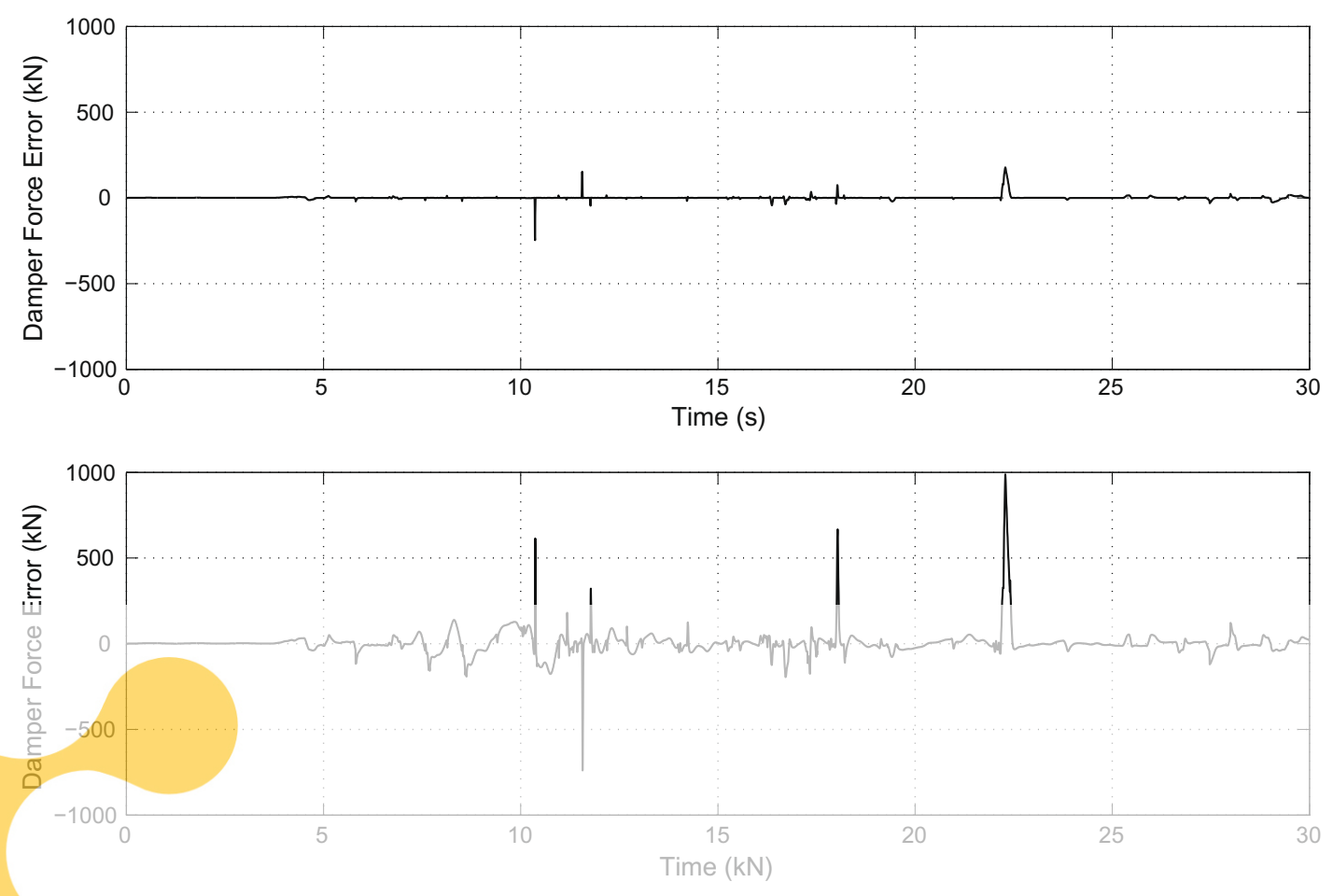

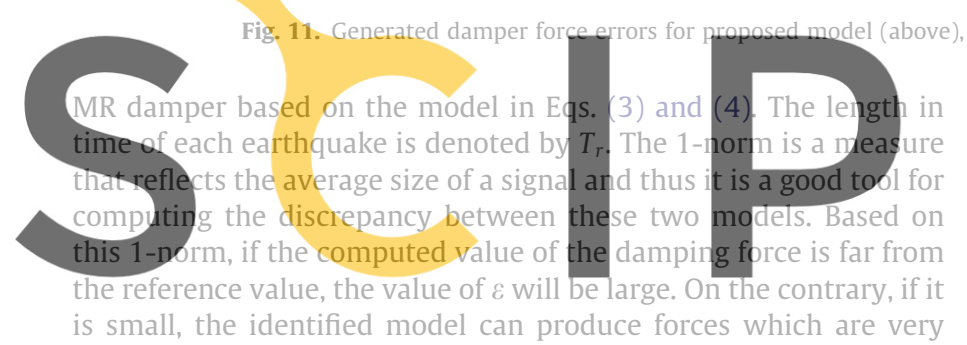

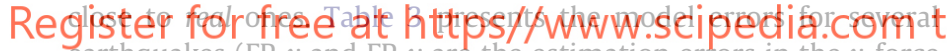
earthquakes (FP- $x$ and FP- $y$ are the estimation errors in the $x$-force and $y$-force directions). A sample earthquake record and the corresponding command voltage during the control process are presented in Fig. 9. In this application, the MR damper is used as a semi-active device in which the voltage is varying by a feedback control loop [8].

\subsection{Comparison of results}

It is interesting to compare the resulting model errors in Table 3 with the resulting model errors when the parameter identification is performed with the model in Eqs. (1) and (2). Table 4 shows the values of the errors for this case. By comparing these two tables, the proposed parameter identification algorithm is clearly more accurate than the method presented in [17].

Fig. 10 shows the comparison between the output force of the black box MR damper during the simulation of the benchmark building under Kobe earthquake, with the two identified models, the proposed one and the model in [17]. Since the two plots in Fig. 10 (top) are very close, Fig. 11 shows the corresponding errors in both cases.

\section{Conclusion}

This paper has proposed an extension of a parameter identification method for MR dampers. This extension allows to identify a larger class of MR dampers more accurately. The validation of the parameter identification method has been carried out using a black box model of an MR damper in a smart base-isolated benchmark

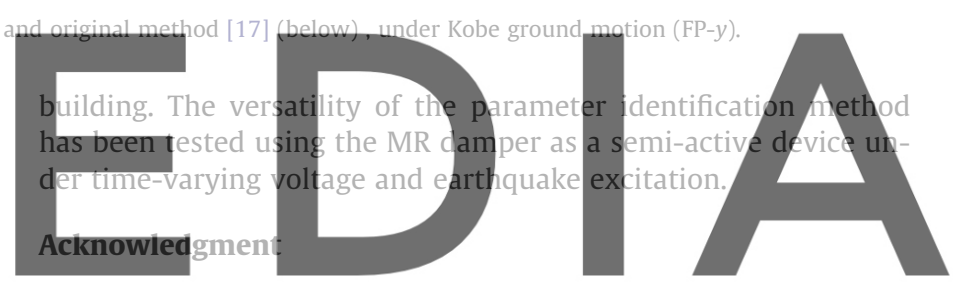

Supported by CICYT (Spanish Ministry of Science and Innova-

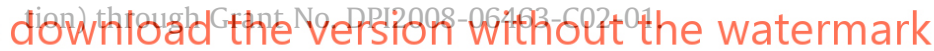
Appendix A

The parameter identification in [18] departs from the next shear-mode model:

$\Phi_{n}(\dot{x})(t)=\kappa_{\dot{x}}(v) \dot{x}(t)+\kappa_{w}(v) w(t)$,
$\dot{w}(t)=\rho\left(\dot{x}(t)-\sigma|\dot{x}(t)||w(t)|^{n-1} w(t)+(\sigma-1) \dot{x}(t)|w(t)|^{n}\right)$,

where $\kappa_{\dot{x}}>0, \kappa_{w}>0, \rho>0, \sigma>1 / 2$, and $n \geqslant 1$. All of these parameters can be voltage or current dependent (here the case of voltage dependency is under consideration, as emphasized for $\kappa_{\dot{x}}$ and $\kappa_{w}$ ). It has been shown in [7] that this model is meaningful in the sense that the limit cycle depends directly on the parameters that appear in the normalized form, and thus depends only indirectly on the parameters of the standard form as

$$
\begin{aligned}
& \rho=\frac{A}{D z_{0}}>0, \\
& \sigma=\frac{\beta}{\beta+\gamma} \geqslant 0, \\
& \kappa_{\dot{x}}=\alpha k>0, \\
& \kappa_{w}=(1-\alpha) D k z_{0}>0,
\end{aligned}
$$

where $A, D, \alpha, \beta, \gamma$ and $k$ comes from the standard Bouc-Wen model $\Phi_{\mathrm{BW}}(x)(t)=\alpha k x(t)+(1-\alpha) D k z(t)$, $\dot{z}=D^{-1}\left(A \dot{x}-\beta|\dot{x}| z|z|^{n-1}-\gamma \dot{x}|z|^{n}\right)$.

For parameter identification, a $T$-periodic input $\dot{x}(t)$ (see Fig. 12) is applied to the Bouc-Wen system under constant voltage $v$. It has 


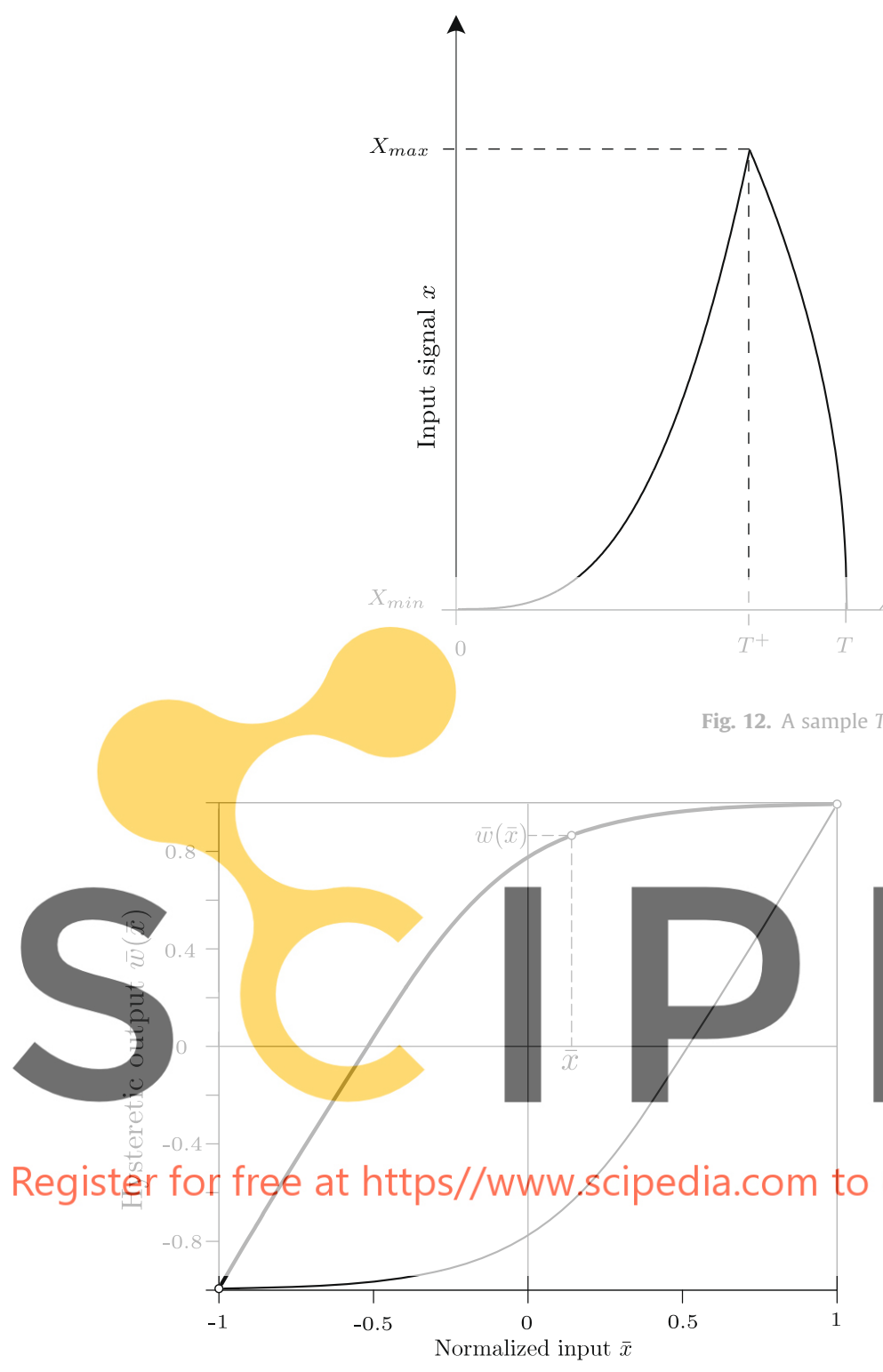

Fig. 13. Symmetry property of the hysteresis loop of the normalized Bouc-Wen model.

been proved [7] that the output force of the Bouc-Wen model goes asymptotically to a periodic steady-state so that a limit cycle is obtained. The identification method assumes the knowledge of the relation $\bar{w}(x)$ that describes this cycle as illustrated in Fig. 13. The whole identification process can be summarized as follows.

The parameter $\kappa_{\dot{x}}$ is first determined using the plastic region $(\bar{w} \approx 1)$ of the hysteresis loop by a linear regression for each constant voltage:

$\bar{F}(\tau)=\kappa_{\dot{x}}(v) \dot{x}(\tau)+\kappa_{w}(v)$.

To continue with parametric estimation, a function $\theta$ is computed as:

$\theta(x(\tau))=\bar{F}(x(\tau))-\kappa_{\dot{x}} \frac{d x(\tau)}{d \tau}, \quad \tau \in\left[0, T^{+}\right]$,

which has a unique zero, i.e., there exists a time instant $\tau_{*} \in\left[0, T^{+}\right]$ and a corresponding value $x_{*}=x\left(\tau_{*}\right) \in\left[X_{\min }, X_{\max }\right]$, such that the function $\theta$ is zero. Because $\theta$ is known, then $\dot{x}_{*}$ is also known. Define the quantity

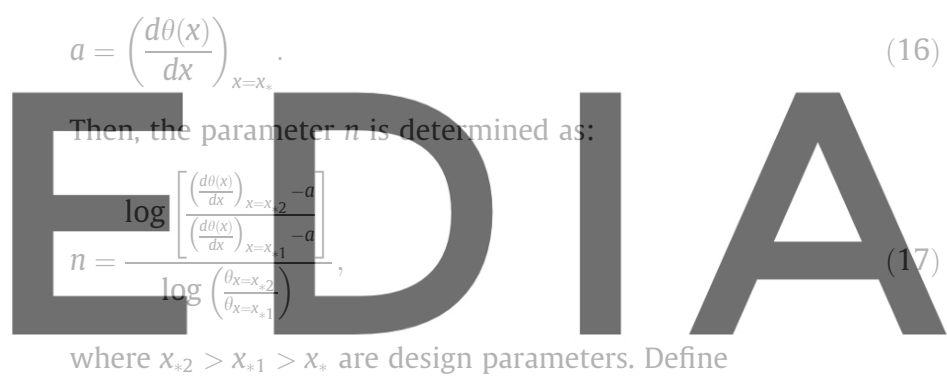

where $x_{* 2}>x_{* 1}>x_{*}$ are design parameters. Define

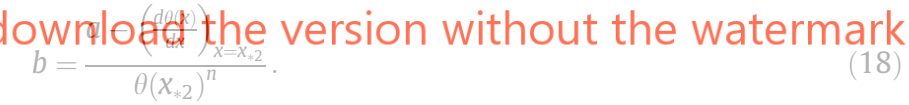

Then, the parameters $\kappa_{w}$ and $\rho$ are computed as follows:

$\kappa_{w}=\sqrt[n]{\frac{a}{b}}$

$\rho=\frac{a}{\kappa_{w}}$.

The function $\bar{w}(x)$ can be computed as:

$\bar{w}(x)=\frac{\theta(x)}{\kappa_{w}}$.

Finally, the remaining parameter $\sigma$ is determined as:

$\sigma=\frac{1}{2}\left(\frac{\frac{\left(\frac{d \bar{w}(x)}{d x}\right)_{x=x_{* 3}}}{\rho}-1}{\left(-\bar{W}\left(X_{* 3}\right)^{n}\right)}+1\right)$,

where $x_{* 3}$ is a design parameter such that $x_{* 3}<x_{*}$.

\section{References}

[1] Bossis G, Khuzir P, Lacis S, Volkova O. Yield behavior of magnetorheological suspensions. J Magnet Magnet Mater 2003;258-259:456-8.

[2] Chooi WW, Oyadiji SO. Design, modelling and testing of magnetorheological (MR) dampers using analytical flow solutions. Comput Struct 2008;86(35):473-82.

[3] Dominguez A, Sedaghati R, Stiharu I. Modeling and application of MR dampers in semi-adaptive structures. Comput Struct 2008;86(3-5):407-15.

[4] Dyke SJ, Spencer Jr BF, Sain MK, Carlson JD. An experimental study of MR dampers for seismic protection. Smart Mater Struct 1998;7(5):693-703. 
[5] Gu ZQ, Oyadiji SO. Application of MR damper in structural control using ANFIS method. Comput Struct 2008;86(3-5):427-36.

[6] Ikhouane F, Hurtado JE, Rodellar J. Variation of the hysteresis loop with the Bouc-Wen model parameters. Nonlinear Dyn 2007;48(4):361-80.

[7] Ikhouane F, Rodellar J. Systems with hysteresis: analysis, identification and control using the Bouc-Wen model. John Wiley and Sons Inc.; 2007.

[8] Jansen LM, Dyke SJ. Semiactive control strategies for MR dampers: comparative study. J Eng Mech 2000;126(8):795-803.

[9] Jolly MR, Bender JW, Carlson JD. Properties and applications of commercial magnetorheological fluids. J Intell Mater Syst Struct 1999;10(1): $5-13$.

[10] Gang J, Sain MK, Pham KD, Spencer Jr BF, Ramallo JC. Modeling MR dampers: a nonlinear black box approach. Proc Am Control Conf 2001:429-34.

[11] Gavin H, Hoagg J, Dobossy M. Optimal design of MR dampers. In: Proceedings of the US-Japan workshop on smart structures for improved seismic performance in urban regions, Seattle, WA; 2001. p. 225-36.

[12] Jiménez-Fabián R, Alvarez-Icaza L. Simultaneous state estimation and parameter tuning in a shear building with a magneto-rheological damper. Struct Control Health Monitor 2008;16(4):483-502.

[13] Jin G, Sain MK, Spencer Jr BF. Nonlinear blackbox modeling of MR-damper for civil structural control. IEEE Trans Control Syst Technol 2005;13(3): $345-55$.

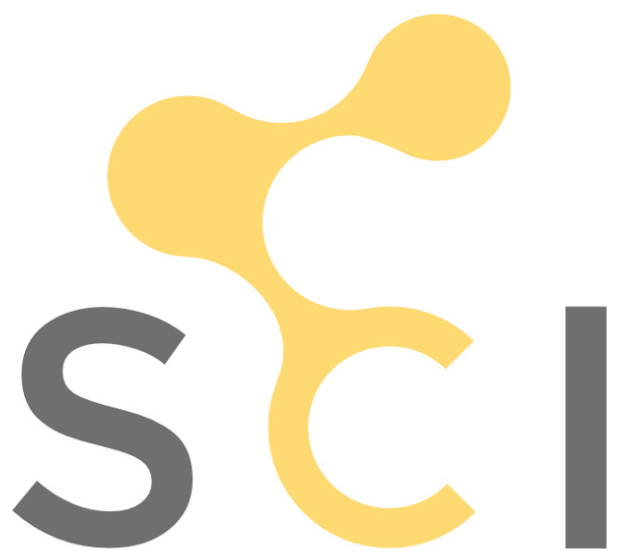

[14] Narasimhan S, Nagarajaiah S, Johnson EA, Gavin HP. Smart base-isolated benchmark building. Part I: problem definition. Struct Control Health Monitor 2006;13(2-3):573-88

[15] Ohtori Y, Christenson RE, Spencer BF, Dyke SJ. Benchmark problems in seismically excited nonlinear buildings. J Eng Mech 2004;130(4):366-85.

[16] Pozo F, Acho L, Rodríguez A, Pujol G. Nonlinear modeling of hysteretic systems with double hysteretic loops using position and acceleration information. Nonlinear Dyn 2009;57(1-2):1-12.

[17] Rodríguez A, Ikhouane F, Rodellar J, Luo N. Modeling and identification of a small-scale magnetorheological damper. J Intell Mater Syst Struct 2009;20(7): 825-35.

[18] Rodríguez A, Iwata N, Ikhouane F, Rodellar J. Model identification of a largescale magnetorheological fluid damper. Smart Mater Struct 2009;18(1). doi:10.1088/0964-1726/18/1/015010.

[19] Savaresi SM, Bittanti S, Montiglio M. Identification of semi-physical and black box nonlinear models: the case of MR dampers for vehicles control. Automatica 2005;41(1):113-27.

[20] Spencer Jr BF, Dyke SJ, Sain MK, Carlson JD. Phenomenological model of a magnetorheological damper. J Eng Mech 1997;123(3):230-8.

[21] Spencer BF, Nagarajaiah S. State of the art of structural control. J Struct Eng 2003;129(7):845-56.

[22] Wen YK. Method for random vibration of hysteretic systems. J Eng Mech 1976;102(2):249-63.

\section{Register for free at https//www.scipedia.com to download the version without the watermark}

